\title{
Proposition of an Empirical Functional Equation to Predict the Kinetics of Austenite to Ferrite Transformation in a Continuous Cooled IF-Ti-Stabilized Steel
}

\author{
Ana Luiza Soares Cezário ${ }^{a}$, Geraldo Lúcio de Faria ${ }^{a *}$ (1) \\ ${ }^{a}$ Universidade Federal de Ouro Preto, 35400-000, Ouro Preto, MG, Brasil
}

Received: October 30, 2020; Revised: December 15, 2020; Accepted: December 27, 2020

\begin{abstract}
The kinetics of phase transformations in isothermal processes is well described by the classic JMAK model. However, it is known that most industrial facilities employ continuous cooling processes and, for this condition, the JMAK model is adapted but, sometimes, without success. Considering the importance to predict critical temperatures, the present work proposes an alternative empirical functional equation to describe the kinetics of steel phase transformation under continuous cooling, being useful when the JMAK use is not successful. In this study, the continuous cooling austenite to ferrite transformation was experimentally characterized by dilatometry for an IF-Ti-stabilized steel. The proposed equation was compared with the classic adapted JMAK model regarding to evaluate its efficacy to fit the dilatometric experimental data. Using the constants obtained by the both model fittings as input parameters, a computational simulation was performed to determine the CCT diagram of the IF-Ti steel. The proposed functional equation was efficient to predict the critical temperatures, the kinetics of austenite decomposition and the CCT diagram of the studied steel. The results predicted by the proposed model greatly met the experimental data measured by dilatometry.
\end{abstract}

Keywords: Empirical equation, phase transformation, continuous cooling, IF-Ti-stabilized steel.

\section{Introduction}

The knowledge about the mechanisms and kinetics of phase transformation in steels is relevant when one wishes to evaluate the development of material microstructures in function of its processing history, as well as to understand the relation between its structure and its properties ${ }^{1-7}$.

Since 1930 decade, the physical metallurgy researchers invest their efforts to understand, to describe and to predict the kinetics of steel phase transformations. The pioneer studies evaluated the isothermal phase transformation, consolidating important physical models and predicting equations. The kinetics of isothermal phase transformations is well described by the classic Johnson-Mehl-Avrami-Kolmogorov (JMAK) model, presented in Equation 1. In this equation, $y$ is the fraction of the new transformed phase after a certain time $(t)$; $n$ is the Avrami exponent and $k$ depends on the transformation temperature and it is predicted by the Arrhenius equation (Equation 2), where $k_{O}$ is the pre-exponential coefficient, $R$ is the universal gas constant and $Q$ is the global activation energy for phase transformation, incorporating activation enthalpies of all the atomic processes that constitute the global phase transformation ${ }^{8-10}$.

$$
\begin{aligned}
& y=1-\exp \left(-k t^{n}\right) \\
& k=k_{0} \exp \left(-\frac{Q}{R T}\right)
\end{aligned}
$$

However, the most industrial facilities employ, on their steel processing routes, continuous cooling stages, where

*e-mail: geraldolfaria@yahoo.com.br for different steel types, the austenite decomposes, defining the product final microstructure, as well as its mechanical properties. In this context, many researchers have been studying this problem until nowadays, and have been proposing physical models to predict the kinetics of phase transformation under continuous cooling. However, most part of this physical models are very complex, assume many physical simplifications and require powerful computational resources, making them difficult to apply in the industrial environment ${ }^{3,5,11-19}$.

Considering this scenario, many researchers and steel manufacturers perform a mathematical adaptation of JMAK equation to predict continuous cooling phase transformations, although the physical understanding of the model is partially disregarded. Several authors related that this mathematical adaptation, due to the sigmoidal profile of the JMAK equation, is an easy, simple and trustable way to model and to predict the phase transformations as a time function for a continuous cooled steel ${ }^{3,12,15-21}$. However, some authors also reported unsatisfactory fitting of JMAK equation to experimental data collected during some steel continuous cooling transformation, i.e. a relatively low convergence, leading sometimes to relatively low coefficient of determination $\left(\mathrm{R}^{2}\right)$ and, consequently, to great predictability deviations ${ }^{18,21}$.

The interstitial free (IF) steels have relatively simple chemical composition. They contain ultra-low carbon and nitrogen contents with small additions of strong carbonitride forming elements such $\mathrm{Ti}$ and $\mathrm{Nb}$. IF steels are widely used in the automotive industry, being usually drawn and welded. Aiming to improve the steel manufacturing processes, as well as the post-welding microstructures, the understanding of the 
kinetics of the primary phase transformations (austenite $\rightarrow$ ferrite) is relevant. As the IF steels may be manufactured and applied with different chemical compositions and their final ferrite morphologies depend on the steel cooling condition, to characterize and to predict the austenite $\rightarrow$ ferrite transformation is a great contribution to the material processing planning ${ }^{1,22-24}$.

It is known that most industrial facilities employ continuous cooling processes in IF steels. Therefore, to model its phase transformation kinetics under continuous cooling is important in order to have predictability of critical temperatures and transformation rates, allowing to improve the material processing. Cezário et al. ${ }^{21}$, studying IF steels welded by the TIG process, reported that the adaptation of JMAK equation to predict the critical temperatures related to the austenite $\rightarrow$ ferrite transformation was not satisfactory, presenting a relatively great deviation. Motivated by this, they proposed a direct equation to obtain critical temperatures as a function of the steel cooling rate. However, their equation did not allow to predict the transformed phase fraction as a time function, which it is important for many applications. They also reported that several models have been proposed by researchers for predictability of phase transformation in continuous cooling, however they did not use them because they are either of high computational complexity, or use different adaptations of the JMAK model that did not fit satisfactorily to their IF experimental data ${ }^{5,25-27}$.

Therefore, the present work aims to propose a relatively simple and alternative functional equation to mathematically predict the kinetics of phase transformation of an IF-Ti-stabilized steel submitted to continuous cooling transformations. The adapted JMAK equation was also applied to the experimental data and the results were compared. Samples of the IF-Ti steel were subjected to dilatometric tests at different cooling rates in a quenching dilatometer and, subsequently, the provided data were treated and analyzed, and the feasibility of using the proposed model was investigated. The main goal of this research is to propose a simple empirical equation (even without physical meanings) that allows to predict the kinetics of phase transformation and to calculate the CCT diagram of the IF-Ti steel, for any cooling rate, without the need to use complex physical models or powerful computational resources.

\section{Materials and Methods}

The material used in this study was an IF-Ti-stabilized steel and its nomenclature in this work will be IF-Ti. The steel chemical characterization was performed using the Optical Emission Spectrometry technique, in the Foundry-Master Xpert equipment - Oxford Instruments. The initial microstructure of the IF-Ti steel was characterized applying standardized metallographic procedures to a representative sample ${ }^{28}$. The sample was etched with Nital $2 \%$ and it was analyzed in a Leica DM2700M optical microscope. In addition, the sample was submitted to Vickers microhardness tests ${ }^{29}$ in a digital Pantec microhardness tester using a load of $50 \mathrm{gf}$ and the application time of $15 \mathrm{~s}$. To calculate the average Vickers microhardness, 15 random measurements were performed.

After the initial chemical and microstructural characterization, cylindrical dilatometric specimens of the IF-Ti steel were machined with standardized size of $10 \mathrm{~mm}$ in length and $3 \mathrm{~mm}$ in diameter. The dilatometric tests were performed heating each sample $\left(5^{\circ} \mathrm{C} / \mathrm{s}\right)$ to $1100{ }^{\circ} \mathrm{C}$ with a
3 min. soaking time for complete austenitizing. After that, each sample was continuously cooled with a specific cooling $\operatorname{rate}\left(0.5^{\circ} \mathrm{C} / \mathrm{s}, 1^{\circ} \mathrm{C} / \mathrm{s}, 5^{\circ} \mathrm{C} / \mathrm{s}, 10^{\circ} \mathrm{C} / \mathrm{s}, 20^{\circ} \mathrm{C} / \mathrm{s}\right.$ and $\left.100^{\circ} \mathrm{C} / \mathrm{s}\right)$.

After performing the dilatometric tests, the heating and the cooling data of each dilatometric curve were transferred to the OriginPro 9.0 software for mathematical work. For each experiment, the relative length $\left(\varepsilon=\frac{\Delta L}{L_{0}}\right)$ was plotted as a temperature function. Then, in the same graph, the first order derivative curve was plotted to determine the phase transformation critical temperatures ${ }^{30}$. The dilatometric heating curve was analyzed with the purpose of determining the critical temperatures $\mathrm{Ac}_{1}$ and $\mathrm{Ac}_{3}$, while the cooling dilatometric curves, besides providing the critical temperatures $\mathrm{Ar}_{3}$ and $\mathrm{Ar}_{1}$, were also used to study the kinetics of austenite to ferrite decomposition at different cooling rates.

To perform the kinetic study, for each evaluated cooling rate, the lever rule was applied to the relative length $\left(\varepsilon=\frac{\Delta L}{L_{0}}\right)$ versus temperature data and it was possible to obtain, for each studied condition, the austenite and ferrite fractions as a temperature function. The lever rule applied to the dilatometric data is a well-known and well-established method to quantify the phase fractions of biphasic systems ${ }^{3-5,13,18-21}$, as it was supposed for the studied steel. An example illustrating how this was performed will be further presented in Results and Discussion section.

Known phase fraction values as a temperature function for each evaluated cooling rate, the first form of the proposed equation, relating phase fraction to the instantaneous temperature (Equation 3), was fitted to these generated data. As all experiments were performed with constant cooling rates, the Equations 4 and 5 could be applied to calculate de temperature-time relations. This made possible to plot the phase fractions as a time function. In this graph (phase fraction $\mathrm{x}$ time), two different fittings were performed, the first considering the classic JMAK model (Equation 1) and the second considering the final form of the proposed equation, given by Equation 6 (which directly relate phase fraction as a time function). For each analyzed cooling rate, the $k, n$ and $T_{f}$ constants were obtained. These constants were later used as input parameters to simulate the ferrite formation kinetics and to simulate the CCT diagram of the IF-Ti steel.

The CCT diagram of the IF-Ti steel was built considering the experimentally determined critical temperatures and the ones obtained considering both JMAK model and the proposed equation. The calculation of the critical temperatures considering both mathematical ways was carried out from the simulation of the ferrite formation kinetic, in which the transformation beginning was taken as being the temperature referring to $1 \%$ of formed ferrite and the transformation end to be that temperature in which the formed ferrite fraction is $90 \%$. Aiming to allow the predictability of ferrite formation kinetics for any rate in the range of studied data, using the proposed model, empirical relations between the parameters $k, n$ and $T_{f}$ (Equation 6) with the cooling rate were established; and a computational calculation were performed, presenting as final result the $\mathrm{Ar}_{3}$ and $\mathrm{Ar}_{1}$ temperatures as a cooling rate function. It is important to highlight that the computational calculations, that will be better described in Results and 
Discussion, as a part of the method development, were performed using the Microsoft Excel 2016, a relatively common software available in the most of the academic and industrial environments.

The tested dilatometric specimens were mounted and submitted to standardized metallographic preparation procedures $^{28}$. They were chemically etched with $2 \%$ Nital and, images of their microstructures were obtained. With the aid of the LAS4.6 software coupled to the Leica optical microscope, it was possible to measure the average grain size of the ferritic grains by automatic determination of the equivalent diameter ${ }^{31,32}$ and, then to evaluate the influence of the cooling conditions on the IF-Ti steel microstructure. In addition, the samples were also submitted to Vickers microhardness tests ${ }^{29}$ applying similar conditions to those performed for the sample in the initial state.

\section{Results and Discussion}

\subsection{Chemical analysis and microstructural characterization}

Table 1 presents the chemical composition of the studied steel. It is observed that the element contents, mainly $\mathrm{C}$ and
Ti, meet the usual values to consider it as an interstitial free Ti stabilized steel ${ }^{33-36}$.

Figure 1 presents the microstructure of the initial state of the IF-Ti steel acquired by optical microscopy (OM). It is observed that, as expected, the material is constituted mainly by a ferritic matrix with the presence of Ti carbonitrides ${ }^{33-36}$. The ferritic average grain size at this condition was $(20.82 \pm 0.08) \mu \mathrm{m}$ and the average Vickers microhardness was $(95 \pm 5) \mathrm{HV}$.

\subsection{Dilatometric tests aiming to determine critical temperatures}

Figure 2a shows an example of a dilatometric curve obtained during the IF-Ti steel heating and its respective derivative curve used to determinate $\mathrm{Ac}_{1}$ and $\mathrm{Ac}_{3}$ critical temperatures. It is observed that the beginning of the specimen contraction represents the start of the $\alpha \rightarrow \gamma$ transformation, this occurs due to the lower molar volume of austenite compared to the ferritic one ${ }^{37}$. Six similar curves were obtained and, for each one, the start and end austenitizing temperatures were determined. Figure $2 \mathrm{~b}$ highlights these measured critical temperatures related to the IF-Ti steel austenitizing ( $\mathrm{Ac}_{1}$-start, $\mathrm{Ac}_{3}$-end). It is observed that the $\mathrm{Ac}_{1}$ and $\mathrm{Ac}_{3}$ average values was $891{ }^{\circ} \mathrm{C}$ and $1032{ }^{\circ} \mathrm{C}$ respectively.

Table 1. Chemical composition of the IF-Ti steel studied in this work (wt.\%).

\begin{tabular}{ccccccccccc}
\hline Alloy & $\mathrm{C}$ & $\mathrm{Si}$ & $\mathrm{Mn}$ & $\mathrm{P}$ & $\mathrm{S}$ & $\mathrm{Al}$ & $\mathrm{Nb}$ & $\mathrm{Ti}$ & $\mathrm{Mo}$ \\
\hline IF-Ti & 0.004 & 0.028 & 0.10 & 0.013 & 0.010 & 0.03 & 0.0030 & 0.0577 & 0.0132 \\
\hline
\end{tabular}
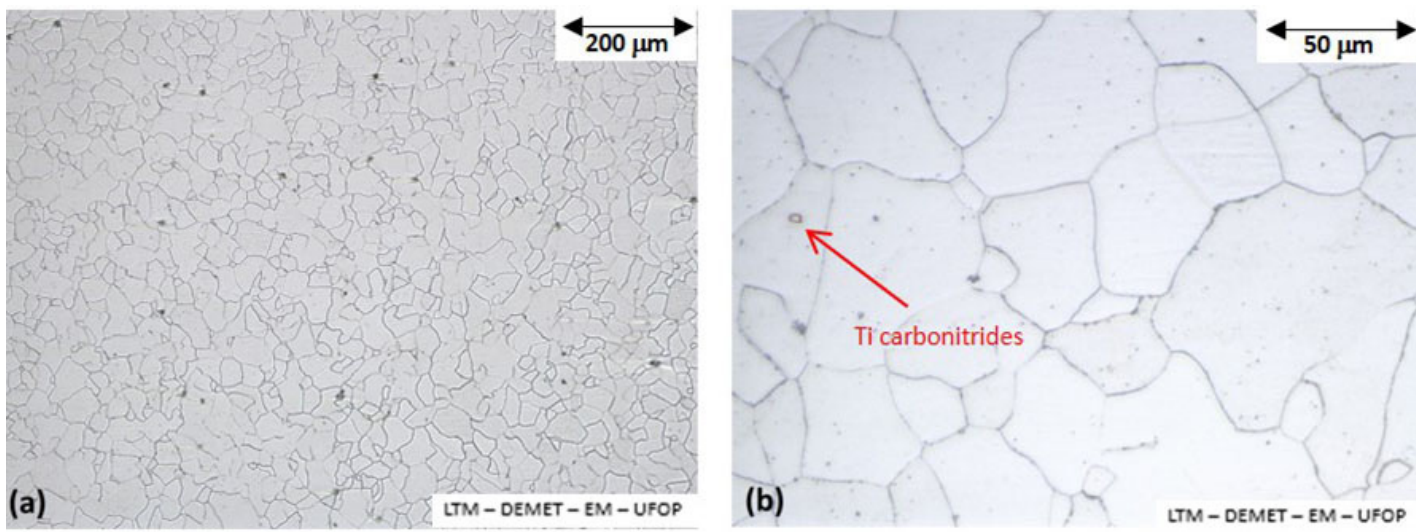

Figure 1. Microstructure of the initial state of IF-Ti steel (a) 100x; (b) 500x. OM - Nital 2\%.
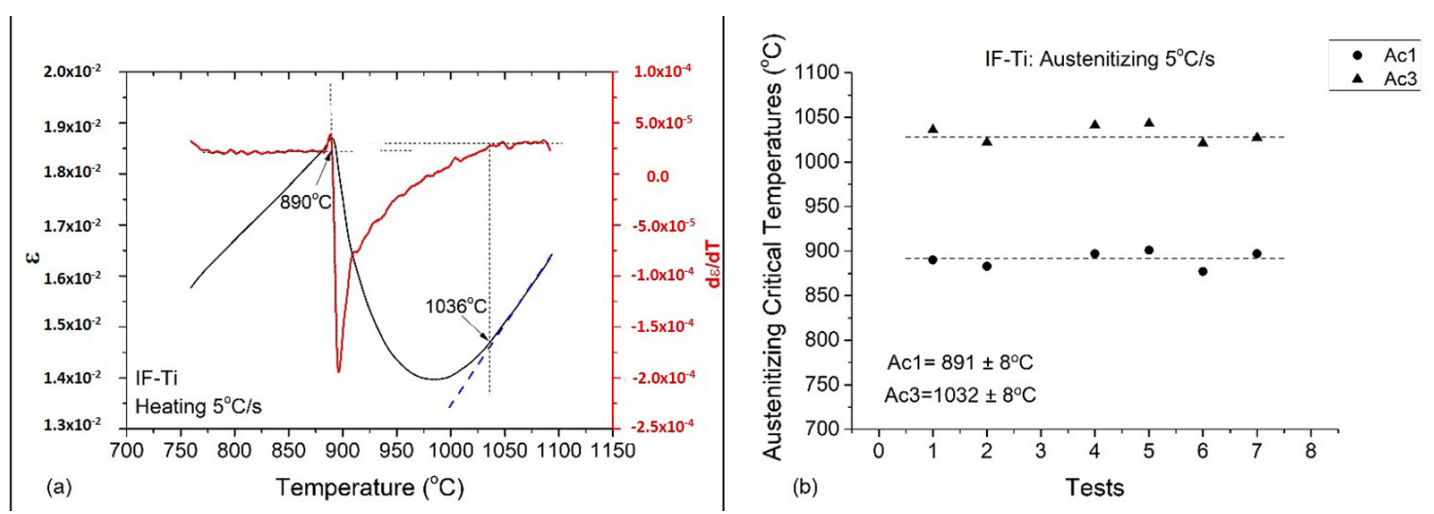

Figure 2. (a) Example of a dilatometric curve of IF-Ti steel continuous heated at $5{ }^{\circ} \mathrm{C} / \mathrm{s}$ constant rate; (b) $\mathrm{Ac}_{1}$ and $\mathrm{Ac}_{3}$ critical temperatures experimentally determined for the IF-Ti steel. 
Figure 3a presents an example of a dilatometric curve obtained during the steel continuous cooling at a rate of $1{ }^{\circ} \mathrm{C} / \mathrm{s}$ and its respective derivative curve used to determine $\mathrm{Ar}_{1}$ and $\mathrm{Ar}_{3}$ critical temperatures. It is emphasized that for each studied cooling rate, a dilatometric curve was obtained and similarly treated. Figure $3 \mathrm{~b}$ presents the measured critical temperatures, related to the $\gamma \rightarrow \alpha$ transformation as a function of the different evaluated cooling rates. During the steel cooling, ferrite grains preferentially nucleate in the austenite grains boundaries at temperatures around $\mathrm{Ar}_{3}$ and then grow continuously, consuming all austenite. It is observed that increasing the cooling rate, the transformations will begin and finish in lower temperatures, result of a higher austenite undercooling ${ }^{24}$.

For alloyed steels it is expected that increasing the cooling rate, solid solution elements have a great effect on the austenite undercooling. As the austenite to ferrite transformation is a diffusional mechanism, the cooling rate increase can retard the elements diffusion, increasing its content on austenite until lower temperatures, retained it metastable and delaying its decomposition. This behavior was observed in the IF-Ti studied steel, but due to its low carbon and low alloying element contents, the effect of increasing cooling rate on the austenite undercooling is not so intense as the described for alloyed or microalloyed steels ${ }^{38-42}$. Higher cooling rates decrease the austenite to ferrite transformation temperature, increasing the austenite decomposition driving force. As consequence, the increased cooling rates should promote the reduction of the critical radius for ferrite nucleation, favoring the ferrite nucleation rate and promoting a ferrite grain refinement ${ }^{38,39}$.

Another factor that probably contributed to the differences in ferrite grain sizes were the coarsening of previous austenite grains for the lowest evaluated cooling rates. As the austenite grains grow relatively fast in IF steels, the samples submitted to the lowest cooling rates remained higher periods of time in temperatures above $\mathrm{Ac}_{3}$ temperature, allowing austenite grain coarsening compared to the samples submitted to higher cooling rates. The coarser the austenite structure the lower the density of preferential sites for ferrite nucleation and, therefore, the higher the ferrite grain size.
The samples submitted to dilatometric experiments were microstructurally characterized by optical microscopy (OM). Figure 4 presents the obtained micrographs. It is possible to observe that increasing the steel cooling rate and lowering the transformation start temperature, a ferritic grain refinement has occurred. The ferrite average grain sizes and the average Vickers microhardness for each analyzed rate are presented in Table 2. It is clear that the microhardness values increased as the average grain size decreased, due probably to the increase of grain boundary and dislocation densities, favoring the material mechanical strength ${ }^{41}$. It is important to highlight that due to the fact that there is not a great influence of the cooling rate on the austenite undercooling for the studied steel, a large variation in the austenite decomposition driving force was not expected, and therefore, neither in the ferrite nucleation rate, thus justifying the small variation in ferritic grain size, mainly for cooling rates between $5^{\circ} \mathrm{C} / \mathrm{s}$ and $20^{\circ} \mathrm{C} / \mathrm{s}$.

\subsection{Kinetics of austenite to ferrite transformation}

From the dilatometric curves obtained in the continuous cooling of the IF-Ti steel at different rates, it was possible to calculate the austenite fraction according to the methodology below described (lever rule). Firstly, two parallel lines were drawn as Figure 5a presents. Then, an isotherm was traced and, by applying the specific volume variation method (lever rule $)^{38,39,43}$, the austenite fraction was calculated as a temperature function. In order to sample points along the

Table 2. Average ferritic grain sizes and average Vickers microhardness values as a cooling rate function.

\begin{tabular}{ccc}
\hline $\begin{array}{c}\text { Continuous } \\
\text { Cooling Rate } \\
\left({ }^{\circ} \mathrm{C} / \mathrm{s}\right)\end{array}$ & $\begin{array}{c}\text { Average size of } \\
\text { ferritic grains } \\
(\mu \mathrm{m})\end{array}$ & $\begin{array}{c}\text { Vickers } \\
\text { Microhardness } \\
(\mathrm{HV})\end{array}$ \\
\hline 0.5 & $252 \pm 27$ & $80 \pm 3$ \\
\hline 1 & $183 \pm 3$ & $79 \pm 2$ \\
\hline 5 & $127 \pm 12$ & $84 \pm 2$ \\
\hline 10 & $122 \pm 11$ & $95 \pm 7$ \\
\hline 20 & $115 \pm 12$ & $87 \pm 2$ \\
\hline 100 & $83 \pm 6$ & $95 \pm 3$ \\
\hline
\end{tabular}

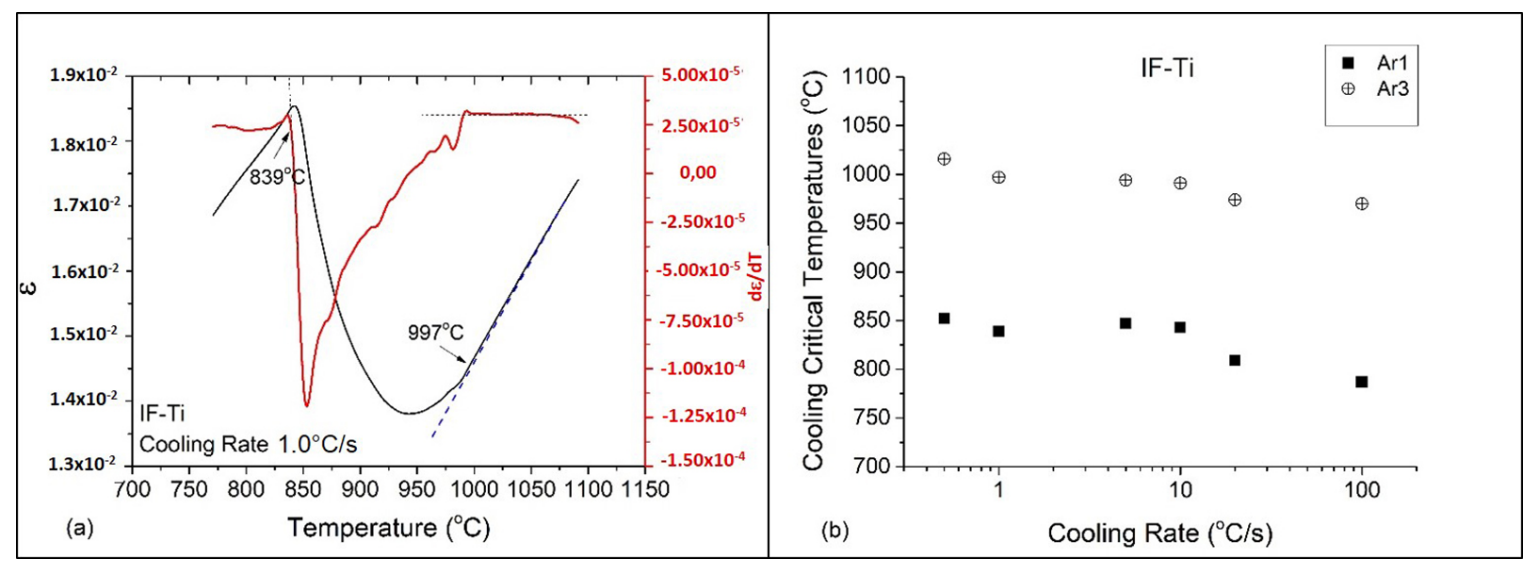

Figure 3. (a) Example of cooling dilatometric curve obtained for a continuous cooling rate at $1{ }^{\circ} \mathrm{C} / \mathrm{s}$; (b) cooling critical transformation temperatures as a function of applied cooling rates. 

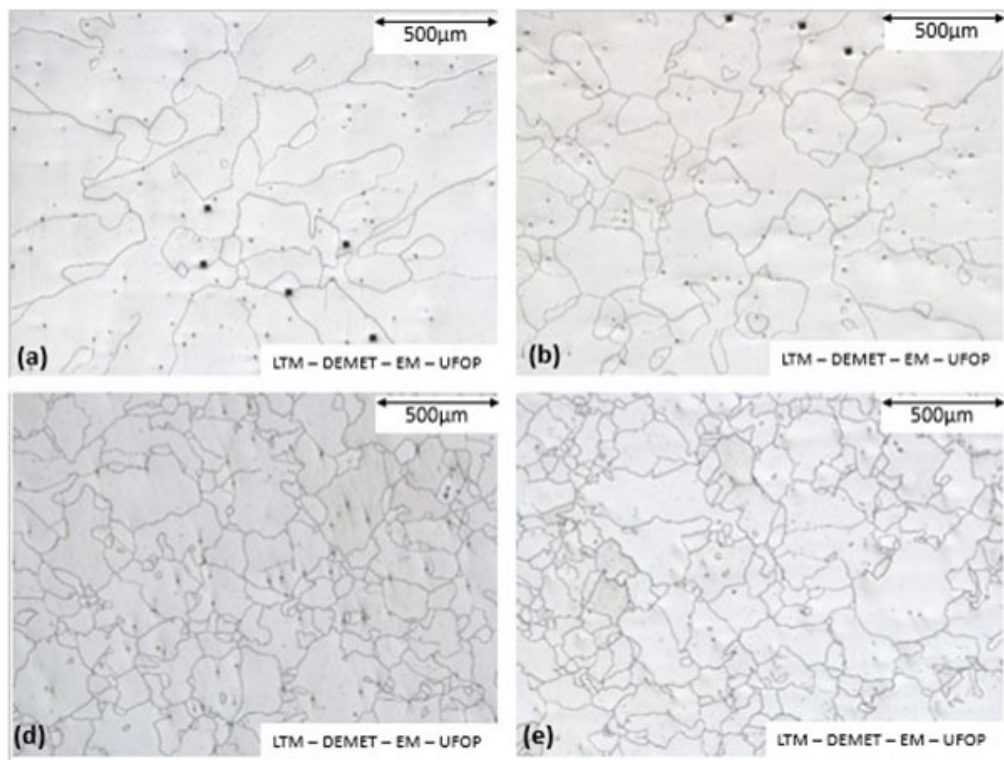

(b)

ITM - DEMET - EM - UFOP
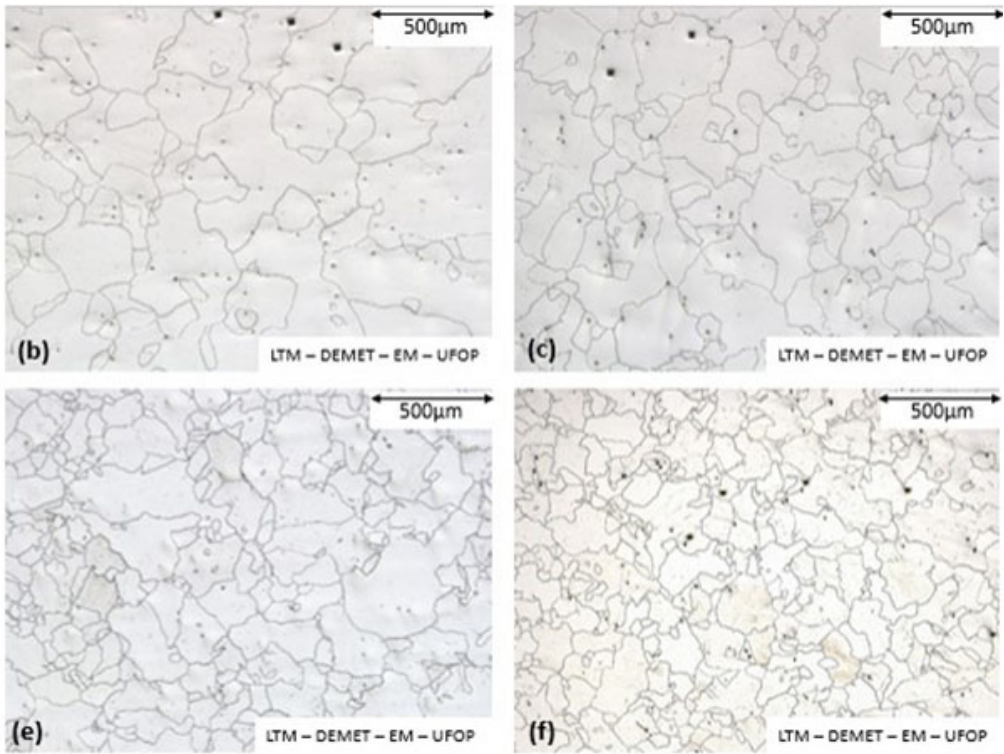

(f)

Figure 4. Microstructures of tested specimens at continuous cooling rates: (a) $0.5{ }^{\circ} \mathrm{C} / \mathrm{s}$; (b) $1{ }^{\circ} \mathrm{C} / \mathrm{s}$; (c) $5{ }^{\circ} \mathrm{C} / \mathrm{s}$; (d) $10{ }^{\circ} \mathrm{C} / \mathrm{s}$; (e) $20{ }^{\circ} \mathrm{C} / \mathrm{s}$; (f) $100{ }^{\circ} \mathrm{C} / \mathrm{s}-\mathrm{OM}-\mathrm{Nital} 2 \%$.

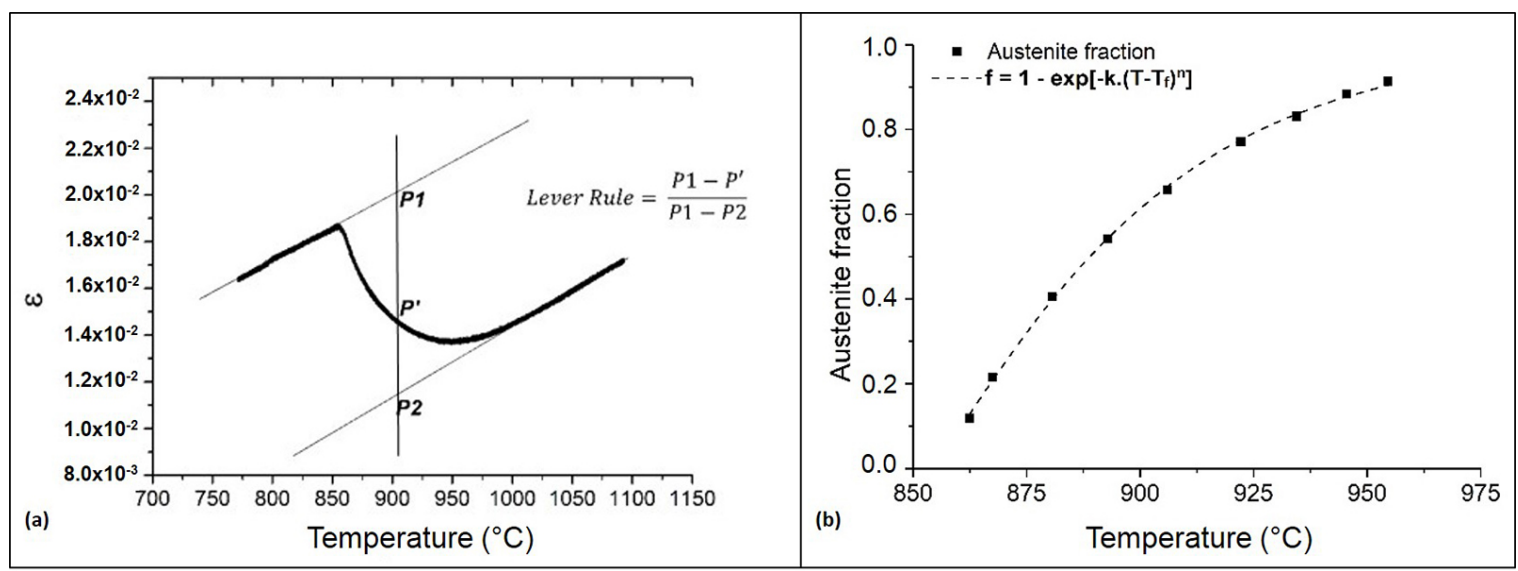

Figure 5. (a) Schematic figure presenting the applied method to calculate the austenite fraction (lever rule); (b) austenite fraction as a temperature function during steel continuous cooling at $0.5^{\circ} \mathrm{C} / \mathrm{s}$.

entire dilatometric curve, the austenite fraction was calculated several times for different temperature values.

For each studied cooling rate, the austenite fractions were plotted as a function of instantaneous temperature, as exemplified in Figure 5b. It is known, and widely described by many authors, that the volumetric fraction of the transformed phase can be fitted by the adapted JMAK model, as far as diffusion processes are concerned and for which the transformed fraction is time dependent ${ }^{8-10,37-39}$. For the phases whose formation is diffusionless and the transformation rate depends on the temperature and do not on the time, as the martensitic one, the Koistinen and Marburger equation is used ${ }^{44}$.

The Koistinen and Marburger equation also has a sigmoidal profile and, disregarding its physical deduction, considering only its mathematical expression and its function geometric profile, it could be possible to establish, using it, a direct relation between the fraction of the formed phase and the instantaneous temperature for continuous cooling transformation, as happens with the martensitic one, even the austenite to ferrite decomposition being diffusional. In view of this and in order to propose an alternative functional equation for mathematical prediction of austenitic decomposition under continuous cooling, with diffusional transformation, a mathematical adaptation of the Koistinen and Marburger equation was proposed. This adaptation is presented by Equation 3, where $y$ is the austenite fraction as a function of the instantaneous temperature $r ; k$ and $n$ are fitting constants and $T_{f}$ is the final temperature of austenite decomposition. Therefore, for each studied cooling rate, the Equation 3 was fitted to the experimental data as exemplified by the Figure $5 \mathrm{~b}$ for the $0.5^{\circ} \mathrm{C} / \mathrm{s}$. The obtained fitting parameters, for each cooling rate, are presented in Table 3 . 


$$
y=1-\exp \left(-k\left(T-T_{f}\right)^{n}\right)
$$

As the studied continuous cooling rates were constant, the instantaneous system temperature $(T)$ can be calculated by Equation 4, where $T_{\gamma}$ is the austenitizing temperature, which in the present work is $1100{ }^{\circ} \mathrm{C}$; rate is the continuous cooling rate corresponding to each studied thermal cycle and $t$ is the elapsed time of the cooling beginning. It should be

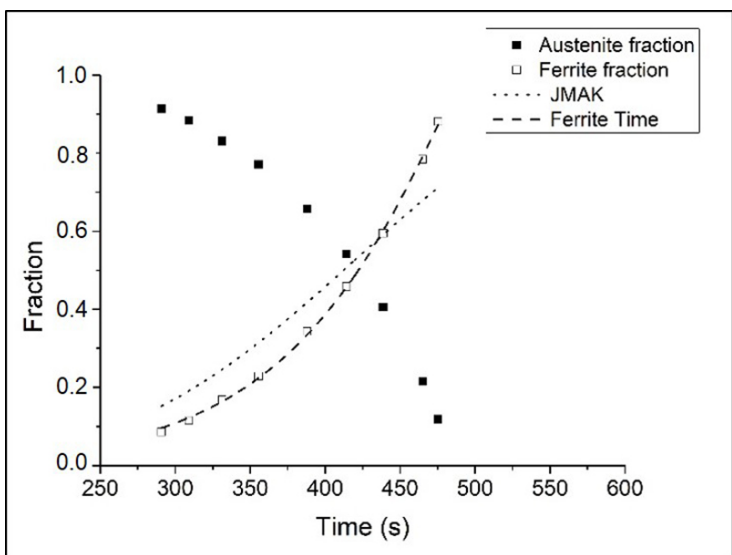

Figure 6. Phase fractions as a time function for IF-Ti steel cooled at $0.5^{\circ} \mathrm{C} / \mathrm{s}$. Comparison between Ferrite-time and JMAK fittings. noted that the rate receives a negative signal in Equation 4, because it is a cooling. Isolating the time from Equation 4, it was possible to write the Equation 5. Using the Equation 5, it was possible to calculate the phase fractions as a function of time, for each one of the studied cooling rates, as Figure 6 exemplifies for the $0.5^{\circ} \mathrm{C} / \mathrm{s}$. The ferrite fraction, in turn, was obtained from the austenite fraction, since it was considered that always the sum of the fractions of the two phases is 1 .

$T=T_{\gamma}+(-$ rate $* t)$

$t=\frac{T_{\gamma}-T}{\text { rate }}$

Substituting the Equation 4 into the Equation 3 and considering that the sum of the fractions of austenite and ferrite phases is equal to 1, Equation 6 is obtained. In this way, the Equation 6 was fitted to the ferrite fraction curve as a function of time, as shown in Figure 6. Then, for comparison, the Equation 1 (classic JMAK equation) was also fitted to the same experimental data. Figure 6 exemplifies a comparison between the proposed equation and JMAK equation for the $0.5^{\circ} \mathrm{C} / \mathrm{s}$ cooling rate, exemplifying what was performed for all studied rates.

Table 4 presents the parameters obtained from the Equation 6, named as Ferrite-Time equation, fitting; while Table 5 presents the parameters related to the JMAK (Equation 1) fitting. It is observed, from Figure 6 and the

Table 3. Kinetics constants obtained by the fitting of Equation 3 to the experimental data.

\begin{tabular}{ccccc}
\hline Cooling Rate $\left({ }^{\circ} \mathrm{C} / \mathrm{s}\right)$ & $k$ & $T_{f}$ & $n$ & $R^{2}$ \\
\hline 0.5 & $1.1 \times 10^{-2}$ & 854 & 1.16 & 0.99915 \\
\hline 1 & $6 \times 10^{-3}$ & 841 & 1.3 & 0.99851 \\
\hline 5 & $2 \times 10^{-3}$ & 845 & 1.5 & 0.99906 \\
\hline 10 & $1 \times 10^{-3}$ & 837 & 1.6 & 0.99819 \\
\hline 20 & $1.8 \times 10^{-3}$ & 814 & 1.5 & 0.99880 \\
\hline 100 & $4 \times 10^{-4}$ & 788 & 1.7 & 0.99908 \\
\hline
\end{tabular}

Table 4. Parameters obtained from the fitting of the Ferrite-Time equation.

\begin{tabular}{ccccc}
\hline \multicolumn{5}{c}{ Proposed Equation: Ferrite-Time } \\
\hline Cooling Rate $\left({ }^{\circ} \mathrm{C} / \mathrm{s}\right)$ & $k$ & $T_{f}$ & $n$ & $R^{2}$ \\
\hline 0.5 & $1.1 \times 10^{-2}$ & 854 & 1.16 & 0.99915 \\
\hline 1 & $6 \times 10^{-3}$ & 841 & 1.26 & 0.99851 \\
\hline 5 & $3 \times 10^{-3}$ & 846 & 1.4 & 0.99887 \\
\hline 10 & $1 \times 10^{-3}$ & 835 & 1.6 & 0.99822 \\
\hline 20 & $2 \times 10^{-3}$ & 814 & 1.5 & 0.99881 \\
\hline 100 & $3 \times 10^{-4}$ & 790 & 1.8 & 0.99883 \\
\hline
\end{tabular}

Table 5. Parameters obtained from the fitting of the JMAK equation.

\begin{tabular}{cccc}
\hline & Classic Model: JMAK & $n$ & $R^{2}$ \\
\hline Cooling Rate $\left({ }^{\circ} \mathrm{C} / \mathrm{s}\right)$ & $k$ & 4 & 0.88124 \\
\hline 0.5 & $1 \times 10^{-11}$ & 5 & 0.92828 \\
\hline 1 & $2 \times 10^{-11}$ & 5.8 & 0.98814 \\
\hline 5 & $3 \times 10^{-10}$ & 5.7 & 0.99600 \\
\hline 10 & $3 \times 10^{-8}$ & 7.1 & 0.99416 \\
\hline 100 & $2 \times 10^{-8}$ & 5.2 & 0.99681 \\
\hline
\end{tabular}


parameters presented in Tables 4 and 5, that the proposed model, identified as Ferrite-Time, fit better to the experimental data than the adaptation of the classic JMAK equation for continuous cooling. The $\mathrm{R}^{2}$ obtained values applying the Ferrite-Time equation are closer to 1 when compared to the ones obtained by the use of JMAK model, even trying to use the linearized form.

$$
y=\exp \left(-k\left(1100+\left(- \text { rate }^{*} t\right)-T_{f}\right)^{n}\right)
$$

\subsection{Kinetics simulation and CCT diagram calculation}

Applying the fitting parameters, obtained for each cooling rate, it was possible to perform two simulations for the ferrite formation kinetics: the first considering the proposed empirical model (Equation 6) and the second considering the classic JMAK model (Equation 1). Equation 6 is the result of adaptations made in Equation 3, in order to establish a direct relationship between ferrite fraction and time. Because of this, it can be seen that the kinetic constants presented in Tables 3 and 4 are similar. However, as it is desired to simulate the transformation evolution directly in terms of time, the data used in this simulation were those presented in Table 4. For the simulation considering the classic JMAK model, the parameters presented in Table 5 were used.

Figure 7 shows and compares the experimental points with simulated curves obtained for both models. It was observed that the simulations of ferrite formation kinetics applying the both analyzed models were satisfactory. It is important to highlight that due to a limitation of mathematical domain presented by Equation 6, it is not possible, as in the JMAK equation, to calculate fractions for time intervals greater than those that return the value 1 . This is not a problem for transformation predictability.

Using the dilatometry technique, the critical temperatures can be experimentally determined only for some specific cooling rates, however an efficient model would allow to predict these temperatures at any cooling rate in the range of studied data. In this work, a simulation to obtain CCT diagrams calculated by the Ferrite-Time Equation and by the model JMAK was attempted, comparing them to the experimentally obtained CCT diagram. In order to make this possible, it would be important to verify the existence of possible mathematical relations between the Equation 6 fitting constants $\left(\mathrm{k}, \mathrm{T}_{\mathrm{f}}\right.$ and $\mathrm{n}$ ) and the cooling rates imposed on the samples. Figure 8 presents the obtained results, as well as Equations 7, 8 and 9 are, respectively, the verified mathematical relations between cooling rate and the parameters $\mathrm{k}, \mathrm{T}_{\mathrm{f}}$ and $\mathrm{n}$.

Applying Equations 7, 8 and 9 it was possible to calculate $k, T_{f}$ and $n$ for any cooling rate value at the studied range, between $0.5{ }^{\circ} \mathrm{C} / \mathrm{s}$ and $100{ }^{\circ} \mathrm{C} / \mathrm{s}$. Therefore, to calculate the CCT diagram of the IF-Ti steel for any cooling rate, the algorithm presented in Figure 9 was used, where it was

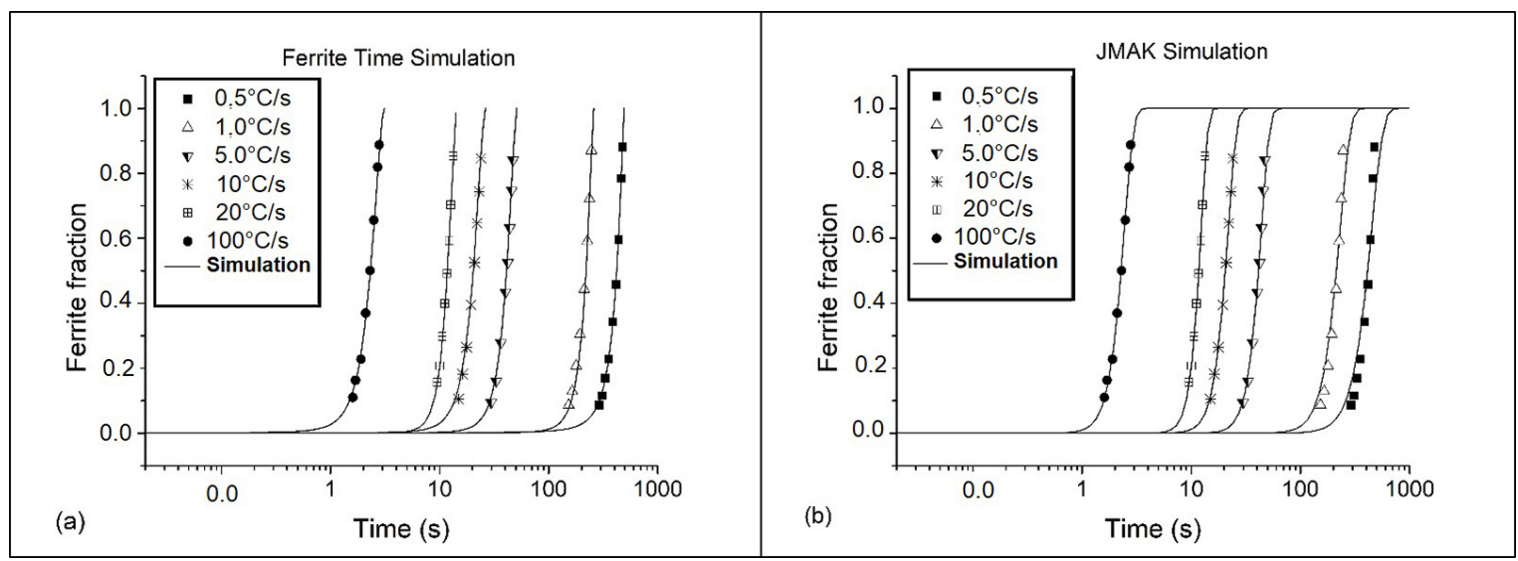

Figure 7. Simulation of ferrite formation kinetics for IF-Ti steel considering (a) Ferrite-Time Model and (b) JMAK Model.

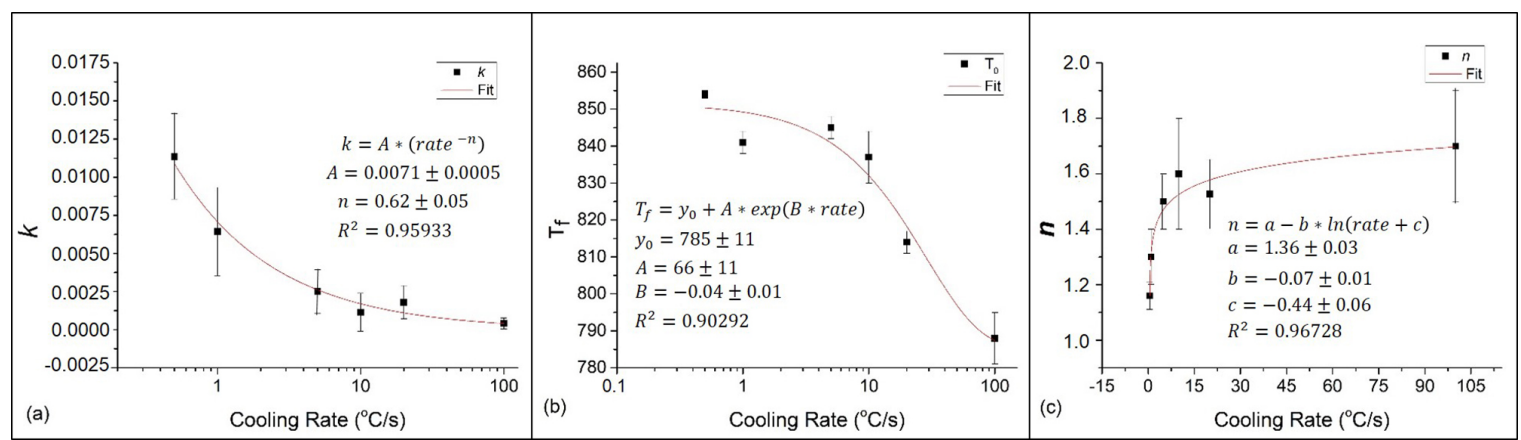

Figure 8. (a) Relation between the constant $k$ and the cooling rate for the IF-Ti steel; (b) Relation between $\boldsymbol{T}_{\boldsymbol{f}}$ and the cooling rate for the IF-Ti steel; (c) relation between $\boldsymbol{n}$ and the cooling rate for the IF-Ti steel. 


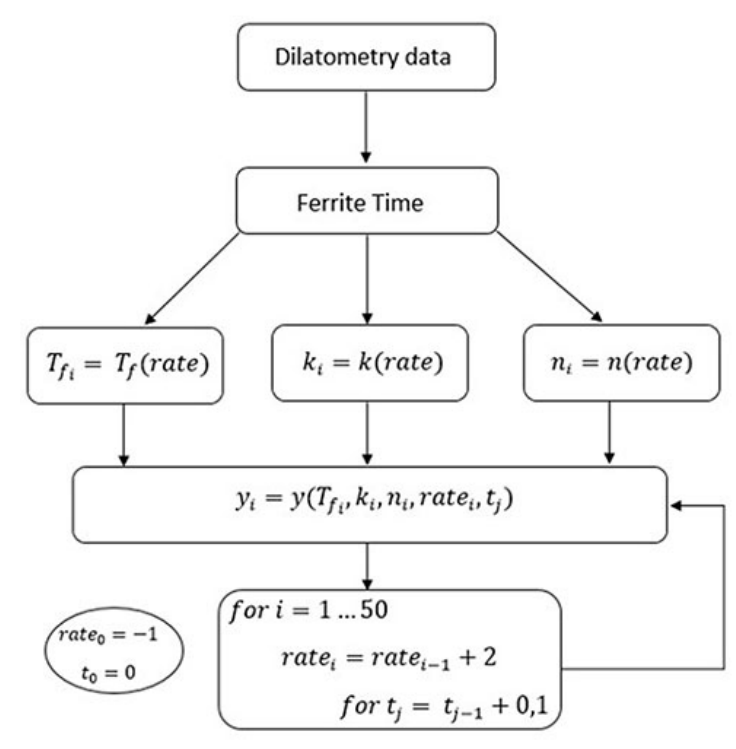

Figure 9. Schematic representation of the used algorithm.

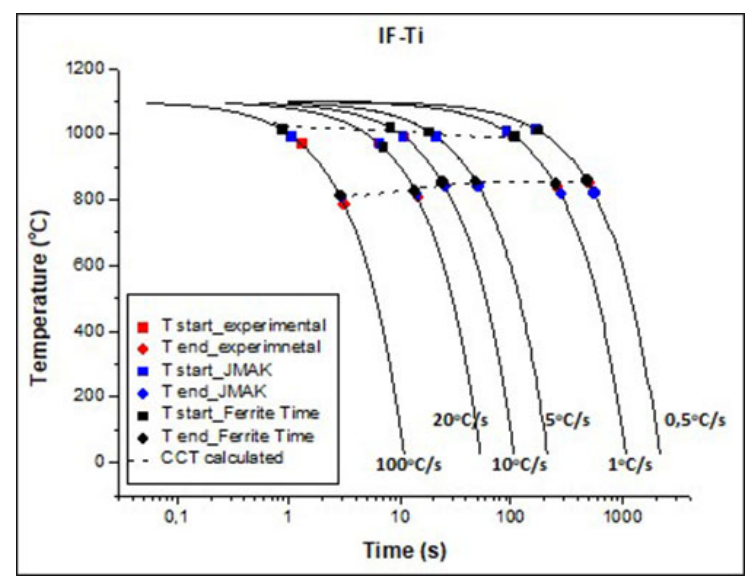

Figure 10. Comparative CCT diagrams presenting the experimental critical temperatures; the critical temperatures calculated by the JMAK method, only for the studied cooling rates (obtained from Figure $7 \mathrm{~b}$ and Equation 4); the critical temperatures calculated by the proposed Ferrite-Time equation (obtained from Figure 7a and Equation 4); and, in addition, the final simulation applying the Ferrite-Time equation (algorithm presented in Figure 9).

proposed that the cooling rate calculation step should be $2{ }^{\circ} \mathrm{C} / \mathrm{s}$ and, for each cooling rate, the time step was $0.1 \mathrm{~s}$. This algorithm allowed to obtain, for each $2^{\circ} \mathrm{C} / \mathrm{s}$ cooling rate interval, the ferrite fraction as a time function. Therefore, using the same criterion presented before (transformation begins at $1 \%$ of formed ferrite and ends at $90 \%$ ) the time intervals corresponding to the beginning and the end of the transformation were obtained. Applying these time intervals to Equation 4, $\mathrm{Ar}_{3}$ and $\mathrm{Ar}_{1}$ were automatically calculated for each cooling rate, making possible the CCT diagram calculation (Figure 10).

$k=A^{*}\left(\right.$ rate $\left.^{-n}\right)$

$T_{f}=y_{0}+A * \exp (B *$ rate $)$ $n=a-b * \ln ($ rate $+c)$

Figure 10 presents a comparison between the different used ways to calculate the CCT diagram of the IF-Ti steel. It compares the experimental critical temperatures, determined by the dilatometric technique with: (a) critical temperatures calculated according to the JMAK method, using the available data presented in Figure $7 \mathrm{~b}$ to determine the time intervals to transformation beginning and end in concomitance with Equation 4; (b) critical temperatures calculated according to the proposed Ferrite-Time equation, using the available data presented in Figure 7a to determine the time intervals to transformation beginning and end in concomitance with Equation 4; and finally the simulated CCT diagram, calculated applying the above presented algorithm. It is possible to observe that the empirical proposed equation was efficient to predict with good agreement the IF-Ti steel CCT diagram for any cooling rate at the studied range.

\section{Conclusions}

The studied steel consists of a ferritic microstructure with the presence of $\mathrm{Ti}$ carbonitrides, as expected due to its chemical composition and thermomechanical processing. The ferritic average grain size of the IF-Ti steel in its initial condition was $(20.82 \pm 0,08) \mu \mathrm{m}$ and its average Vickers microhardness was $(95 \pm 5) \mathrm{HV}$. Considering the initial microstructure of the studied IF-Ti steel and the heating rate of $5{ }^{\circ} \mathrm{C} / \mathrm{s}$, its austenitizing critical temperatures, measured by dilatometry, were $\mathrm{Ac}_{1}=891{ }^{\circ} \mathrm{C}$ and $\mathrm{Ac}_{3}=1032{ }^{\circ} \mathrm{C}$.

Higher cooling rates decreased the austenite to ferrite transformation temperatures, increasing the austenite decomposition driving force and, probably, in association with finer austenitic grains, caused the ferritic grain refinement. As the influence of cooling rate on the austenite undercooling was not so great for the studied steel, a large variation in the austenite decomposition driving force was not expected, and therefore, the ferrite nucleation rate was not strongly increased. This, probably, justifies the relatively small variation in ferritic grain size, mainly for cooling rates between $5{ }^{\circ} \mathrm{C} / \mathrm{s}$ and $20^{\circ} \mathrm{C} / \mathrm{s}$ (decrease of only $9.4 \%$ ).

The dilatometric tests allowed to obtain important experimental data for IF-Ti steel. In addition, for each analyzed cooling rate, it was possible to calculate the austenite and ferrite fractions as temperature and time functions, which enabled the successful fitting of the empirical proposed Ferrite-Time equation, which proved to be efficient to predict, with great agreement, the continuous cooling critical temperatures, the kinetics of austenite to ferrite decomposition and the CCT diagram of the IF-Ti studied steel.

\section{Acknowledgements}

The authors thank the Conselho Nacional de Desenvolvimento Científico e Tecnológico (CNPq) for the financial support.

\section{References}

1. Bayraktar E, Chevalier JP, Kaplan D, Devillers L. Effect of alloying elements on the damage of interstitial free steels. In: SEM Annual Conference; 2009; Albuquerque, New Mexico, 
USA. Proceedings. Society for Experimental Mechanics Inc; 2009.

2. Bhadeshia HKDH. Phase transformations during spot welding of interstitial-free steel. In: International Conference on Interstitial Free Steels: Manufacturing Applications IFSTEEL-2010; 2010; Jamshedpur, India. Proceedings. India: Tata Steel Limited Jamshedpur; 2010. 11 p.

3. Bok HH, Kim SN, Suh DW, Barlat F, Lee MG. Non-isothermal kinetics model to predict accurate phase transformation and hardness of 22MnB5 boron steel. Mater Sci Eng A. 2015;2015(73):67-73.

4. Kong L, Liu Y, Liu J, Song Y, Li S, Zhang R, et al. The influence of chromium on the pearlite-austenite transformation kinetics of the Fe-Cr-C ternary steels. J Alloys Compd. 2015;648:494-9.

5. Li H, Gai K, He L, Zhang C, Cui H, Li M. Non-isothermal phasetransformation kinetics model for evaluating the austenization of 55CrMo steel based on Johnson-Mehl-Avrami equation. Mater Des. 2016;92:731-41.

6. Park J, Jeong H, Jin S, Kim M, Lee K, Kim JJ, et al. Effect of electric current on recrystallization kinetics in interstitial free steel and AZ31 magnesium alloy. Mater Charact. 2017;133:70-6.

7. Lino R, Guadanini LGL, Silva LB, Neto JGC, Barbosa R. Effect of $\mathrm{Nb}$ and $\mathrm{Ti}$ addition on activation energy for austenite hot deformation. Journal of Materials Research and Technology. 2018;8(1):180-8.

8. Kolmogorov AE. On the statistical theory of crystallization of metals. Nauk SSSR. Ser. Mat., 3:355-9.

9. Johnson WA, Mehl RF. Reaction kinetics in process of nucleation and Growth. Transactions of the American Institute of Mining and Metallurgical Engineers. 1939;135:416-42.

10. Avrami MJ. Kinetics of phase change I General Theory. J Chem Phys. 1939;7:1103-12.

11. Gómez M, Medina SF, Caruana G. Modelling of phase transformation kinetics by correction of dilatometry results for a ferritic Nb-microalloyed steel. ISIJ Int. 2003;43(8):1228-37.

12. Singh SB, Krishnan K, Sahay SS. Modeling non-isothermal austenite to ferrite transformation in low carbon steels. Mater Sci Eng A. 2007;445-446:310-5.

13. Lopes MMB, Cota AB. A study of isochronal austenitization kinetics in a low carbono steel. Revista da Escola de Minas. 2014;67:61-6

14. Liu Z, Olivares RO, Lei Y, Garcia CI, Wang G. Microstructural characterization and recrystallization kinetics modeling of annealing cold-rolled vanadium microalloyed HSLA steels. J Alloys Compd. 2016;679:293-301.

15. Chen X, Xiao N, Cai M, Li D, Li G, Sun G, et al. A modified approach to modeling of diffusive transformation kinetics from nonisothermal data and experimental verification. Metall Mater Trans, A Phys Metall Mater Sci. 2016;47:4732-40.

16. Ni J, Wahab MA. A numerical kinematic model of welding process for low carbon steels. Comput Struc. 2017;186:35-49.

17. Xia J, Jin H. Numerical modeling of coupling thermal-metallurgical transformation phenomena of structural steel in the welding process. Adv Eng Softw. 2018;115:66-74.

18. Kohout J. An alternative to the JMAK equation for a better description of phase transformation kinetics. J Mater Sci. 2008;43(4):1334-9.

19. Almeida GMR, Dafé SSF, Oliveira FL, Cota AB. Modeling non-isothermal austenite formation in low carbon steel. REM Int Eng J. 2010;63:293-8.

20. Trzaska J. Empirical formulae for the calculation of austenite supercooled transformation temperatures. Arch Metall Mater. 2015;60:181-5.

21. Cezário ALS, Porcaro RR, Faria GL. Proposition of an empirical model for determination of critical temperatures during continuous cooling in heat affected zones of IF steels welded by the TIG Process. Soldag Insp. 2019;24:1-14.

22. Bayraktar E, Kaplan D, Devillers L, Chevalier JP. Grain growth mechanism during the welding of interstitial free (IF) steels. J Mater Process Technol. 2007;189:114-25.

23. Beladi H, Rohrer GS. The distribution of grain boundary planes in interstitial free steel. The Minerals. Metals \& Materials Society and ASM International. 2013;44A:115-24.

24. Ghosh S, Singh AK, Mula S. Effect of critical temperatures on microstructures and mechanical properties of $\mathrm{Nb}$-Ti stabilized IF steel processed by multiaxial forging. Mater Des. 2016;100:4757.

25. Tomellini M. Kolmogorov-Johnson-Mehl-Avrami kinetics for non-isothermal phase transformations ruled by diffusional growth. J Therm Anal Calorim. 2014;116:853-64.

26. Gao Q, Wang Y, Gong M, Qu F, Lin X. Non-isothermal austenitic transformation kinetics in Fe-10Cr-1Co alloy. Appl Phys, A Mater Sci Process. 2016;122:56.

27. Lei X, Huang J, Jin X, Chen S, Zhao X. Application of JohnsonMehl-Avrami-Kolmogorov type equation in non-isothermal phase process: rediscussion. Mater Lett. 2016;181:240-3.

28. ASTM International. ASTM E3-11: Standard Guide for Preparation of Metallographic Specimens. West Conshohocken: ASTM International; 2017.

29. ASTM International. ASTM E384-17: Standard Test Method for Microindentation Hardness of Materials. West Conshohocken: ASTM International; 2017.

30. Pawłowski B. Determination of critical points of hypoeutectoid steel. Arch Metall Mater. 2012;57(4):957-62.

31. ASTM International. ASTM E112-13: Standard Test Methods for Determining Average Grain Size. West Conshohocken: ASTM International; 2013.

32. ASTM International. ASTM E1382-97: Standard Test Methods for Determining Average Grain Size Using Semiautomatic and Automatic Image Analysis. West Conshohocken: ASTM International; 2015.

33. Hoile S. Processing and properties of mild interstitial free steels. Mater Sci Technol. 2000;16(10):1079-93.

34. Zhao H, Rama SC, Barber GC, Wang Z, Wang X. Experimental study of deep drawability of hot rolled IF steel. J Mater Process Technol. 2002;128:73-9.

35. Saray O, Purcek G, Karaman I, Neindorf T, Maier HJ. Equalchannel angular sheet extrusion of interstitial-free (IF) steel: microstructural evolution and mechanical properties. Mater Sci Eng A. 2011;528:6573-83.

36. Banerjee, K. Physical metallurgy and drawability of extra deep drawing and interstitial free steels. London: IntechOpen Limited; 2012. http://dx.doi.org/10.5772/35073.

37. Gunabalapandian K, Samanta S, Singh SB. Investigation of austenitization in low carbon microalloyed steel during continuous heating. Metall Mater Trans, A Phys Metall Mater Sci. 2017;48(5):2099-104.

38. Cardoso RA, Faria GL. Characterization of austenite decomposition in steels with different chemical concepts and high potential to manufacture seamed pipes for oil and gas industry. Mater Res. 2019;22(5):e20190378.

39. Lima APS, Faria GL, Trindade VB, Cândido LC. Effect of the chemical homogeneity of a quenched and tempered C-Mn steel pipe on the mechanical properties and phase transformations. Mater Res. 2019;22(4):e20180680.

40. Lips K, Yang X, Mols K. The effect of coiling temperature and continuous annealing on the properties of bake hardenable IF steels. Steel Res. 1996;67(9):357-63.

41. Mohrbacher H. Niobium based metallurgical concepts and strategies for the production of IF-HS and IF-BH steel grades. In International Conference on Interstitial Free Steels: 
Manufacturing Applications IFSTEEL-2010; 2010; Jamshedpur, India. Proceedings. India: Tata Steel Limited Jamshedpur; 2010. $12 \mathrm{p}$.

42. Kim J, Jung JG, Kim DH, Lee YK. The kinetics of $\mathrm{Nb}(\mathrm{C}$, $\mathrm{N})$ precipitation during the isothermal austenite to ferrite transformation in a low-carbon Nb-microalloyed steel. Acta Mater. 2013;61:7437-43.
43. Zhao JZ, Mesplont C, De Cooman BC. Kinetics of phase transformations in steels: a new method for analysing dilatometric results. ISIJ Int. 2001;41(5):492-7.

44. Koistinen PP, Marburger RE. A general equation prescribing the extent of the austenite-martensite transformation in pure iron-carbon alloys and carbon steel. Acta Metall. 1959;7:5960 . 